\title{
The etiology and outcome of non-traumatic coma in critical care: a systematic review
}

\author{
Marlene WB Horsting ${ }^{1 * \dagger}$, Mira D Franken ${ }^{1 \dagger}$, Jan Meulenbelt ${ }^{1,2}$, Wilton A van Klei ${ }^{1}$ and Dylan W de Lange ${ }^{1,2}$
}

\begin{abstract}
Background: Non-traumatic coma (NTC) is a serious condition requiring swift medical or surgical decision making upon arrival at the emergency department. Knowledge of the most frequent etiologies of NTC and associated mortality might improve the management of these patients. Here, we present the results of a systematic literature search on the etiologies and prognosis of NTC.

Methods: Two reviewers independently performed a systematic literature search in the Pubmed, Embase and Cochrane databases with subsequent reference and citation checking. Inclusion criteria were retrospective or prospective observational studies on NTC, which reported on etiologies and prognostic information of patients admitted to the emergency department or intensive care unit.

Results: Eventually, 14 studies with enough data on NTC, were selected for this systematic literature review. The most common causes of NTC were stroke (6-54\%), post-anoxic coma (3-42\%), poisoning $(<1-39 \%)$ and metabolic causes (1-29\%). NTC was also often caused by infections, especially in African studies affecting $10-51 \%$ of patients. The NTC mortality rate ranged from 25 to $87 \%$ and the mortality rate continued to increase long after the event had occurred. Also, $5-25 \%$ of patients remained moderately-severely disabled or in permanent vegetative state. The mortality was highest for stroke (60-95\%) and post-anoxic coma (54-89\%) and lowest for poisoning (0-39\%) and epilepsy (0-10\%).

Conclusion: NTC represents a challenge to the emergency and the critical care physicians with an important mortality and moderate-severe disability rate. Even though, included studies were very heterogeneous, the most common causes of NTC are stroke, post anoxic, poisoning and various metabolic etiologies. The best outcome is achieved for patients with poisoning and epilepsy, while the worst outcome was seen in patients with stroke and post-anoxic coma. Adequate knowledge of the most common causes of NTC and prioritizing the causes by mortality ensures a swift and adequate work-up in diagnosis of NTC and may improve outcome.
\end{abstract}

Keywords: Non-traumatic coma, Etiology, Outcome, Mortality, Prognosis

\section{Background}

Coma is a serious condition requiring immediate medical decision making upon arrival at the emergency department or intensive care unit (ICU). As coma can originate from many different etiologies and is life threatening, it represents a challenge for emergency or critical care physicians [1]. Approximately $5 \%$ of the patients present to the emergency department with an

\footnotetext{
* Correspondence: m.w.b.horsting@umcutrecht.nl

${ }^{\dagger}$ Equal contributors

'Division of Anaesthesiology, Intensive Care and Emergency Medicine, University Medical Centre Utrecht, mailstop Q04.2.313, PO Box 85500, 3508 GA Utrecht, Netherlands

Full list of author information is available at the end of the article
}

altered mental state and $1 \%$ of the admissions at the emergency department is due to coma [2]. Coma also is a frequent cause for subsequent admission to the ICU. Although there is no consensus on the precise cut-off point to define coma, in general a GCS lower than 10 points is used [3]. Coma, without a history of a traumatic event, is an accompanying feature of many different conditions, such as severe sepsis, poisoning and hepatic encephalopathy. These conditions or the coma resulting from it, can be fatal if they are not detected or treated adequately [4].

Usually, as a first diagnostic step a differentiation is made between traumatic and non-traumatic coma (NTC).

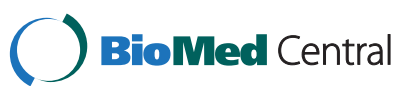

(c) 2015 Horsting et al.; licensee BioMed Central. This is an Open Access article distributed under the terms of the Creative Commons Attribution License (http://creativecommons.org/licenses/by/4.0), which permits unrestricted use, distribution, and reproduction in any medium, provided the original work is properly credited. The Creative Commons Public Domain Dedication waiver (http://creativecommons.org/publicdomain/zero/1.0/) applies to the data made available in this article, unless otherwise stated. 
However, the determination of the cause of NTC is a challenge for the physician. In order to make adequate treatment decisions for patients suffering from NTC, it is vitally important to differentiate its etiology. An important first discrimination should be made between structural causes and non-structural causes of NTC by means of a computer tomography (CT) scan [5]. Structural coma can be due to cerebral infarction, intracranial hemorrhage, intracranial malignancy and central nervous system infection (e.g. encephalitis or abscess). Non-structural coma include coma as a result of poisoning, epilepsy, extracranial infections, circulatory shock, post-anoxic, cardiac arrest, respiratory failure, metabolic problems (such as hypoglycemia, ionic and acid-base disorders, hypothermia), hepatic encephalopathy and uremic encephalopathy [4].

Clearly, knowledge of the most frequent causes of NTC may improve the management of these comatose patients. In this systematic review, we aimed to quantify the causes of non-traumatic coma in an acute medical setting, both on the emergency department or ICU and the mortality associated with it.

\section{Methods}

\section{Literature search}

A systematic literature search was performed in the Pubmed, Embase and Cochrane search engines (Figure 1). In the systematic search "altered mental state" or "nontraumatic coma" in the emergency department or intensive care unit was chosen as domain and the outcome was mortality. For each of these terms, keywords and medical subject heading (MESH) terms were defined to search in title and abstract. Altered mental state was included in the search strategy to prevent exclusion of articles reporting on non-traumatic coma with less strict terminology. The search entry for each database can be found as Additional file 1. All publications prior to May 16th, 2014 were included. All results were independently evaluated by two authors (MH and MF).

\section{Selection of studies}

Only manuscripts written in English were selected. Inclusion criteria were retrospective or prospective observational studies on NTC. For the purpose of this review, NTC was defined as a GCS of 10 or less based on several studies included in this review [3,6-9]. Studies were selected if etiological data and/or prognostic data or mortality rates of patients presenting with NTC at the emergency department or ICU were provided. Exclusion criteria were pediatric patients, traumatic coma, NTC patient sub-populations, publications without prognostic, survival or mortality data of patients presenting with NTC. Search results were first evaluated on title and abstract only (Figure 1). Thereafter, a full publication screening was performed. References of eligible studies were reviewed to identify additional relevant publications. The Web of Science database was used to further identify relevant publications through citation indexing.

\section{Results}

The literature search yielded 9,685 studies, which were evaluated according to the algorithm depicted in Figure 1. Twenty nine articles were selected after screening on title and abstract. Two search results were merely congress abstracts and two articles were not written in English.

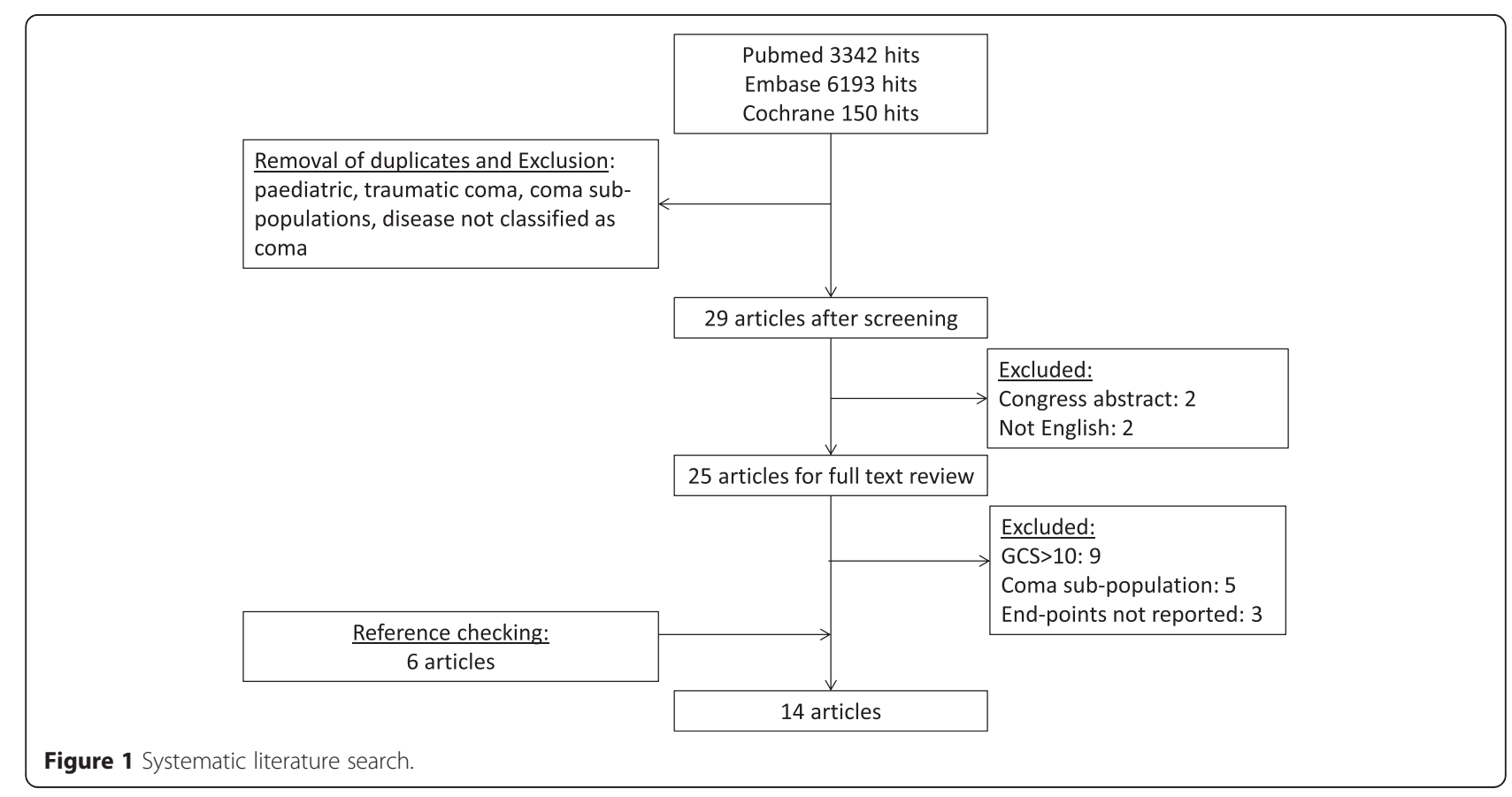


Twenty five articles were selected for full text review. Nine articles were subsequently excluded as the study only reported on patients with altered mental state (GCS $<15$ ) and not exclusively on patients with GCS 10 or less, three articles were excluded because no information on mortality and NTC etiologies was provided, and five articles only reported on a specific coma subgroup. References of eligible studies were reviewed for additional relevant studies, which revealed an additional six publications. In total, 14 publications were selected for this review (Table 1).

\section{Non-traumatic coma etiology}

The most common causes for NTC were stroke (range: 6-54\%), post-anoxic coma (range: 3-42\%), poisoning (range: $<1-39 \%$ ) and metabolic (range: 1-29\%) (Table 2). The prevalence of different causes varied greatly between studies. Infections, including central nervous system infections, were more prevalent in the African studies compared to the other included studies, $10-51 \%$ and $2-9 \%$ respectively [10-13]. Additionally, Owolabi et al. reported HIV related coma in $4 \%$ of patients in their cohort and Matuja et al. reported a high prevalence of cerebral malaria (40\%), while none of the other studies reported on these etiologies as cause of coma $[11,12]$.

Reported prevalence of structural coma varied between $28-64 \%$ and non-structural coma between $37-75 \%$ of patients presenting with non-traumatic coma $[6,9,11,14-17]$. Of note, Weiss et al. only reported a structural coma prevalence of $9 \%$ (cerebrovascular accidents and infections of the central nervous system) [18]. It should however be noted that as this hospital does not have a neurological or neurosurgical ward, this is likely to influence the incidence of reported coma. Hamel et al. only reported a metabolic cause of coma in $1 \%$ of the patients and poisoning in less than $1 \%$ of the patients. The study excluded NTC as a result of drug intoxications and multiple causes of metabolic coma (Table 1) [19].

\section{Outcome}

The primary outcome of interest for this review was mortality. The average mortality rate in NTC patients reported was $25-87 \%$ and varied markedly between studies (Table 1). Patients with stroke had the highest mortality (60-95\%), followed by patients with post-anoxic coma (54-89\%) (Table 3). In contrast, the lowest mortality was found for poisoning and epilepsy: $0-7 \%$ and $0-10 \%$, respectively and $35-67 \%$ for poisoning in the African studies [8,10-13,16,18].

Coma etiology seemed to influence outcome. Sacco et al. reported that coma as a result of poisoning had an eight times higher probability of awaking compared to coma of other etiologies [16]. Additionally, Forsberg et al. reported that coma as a result of poisoning not only resulted in a higher chance of awaking, but also in less neurological sequelae measured with the GlasgowPittsburgh scale $[7,20]$. In their cohort $(n=352), 2 \%$ of patients with coma due to poisoning experienced neurological sequelae defined as permanent vegetative state to moderated disability (disabled but independent) compared to $18 \%$ of patients with coma due to other nontraumatic causes [7]. However, Matuja et al. reported that 4 out of 6 patients with poisoning included in their study died and one patient remained in a permanent vegetative state [11].

Furthermore, Forsberg et al. reported that mortality increased from $27 \%$ at hospital discharge to $39 \%$ in the first year thereafter [21]. This mortality rate was much higher compared to the age matched 1-year mortality in the general population and this was seen in all coma etiologies. Also, even though poisoning and epilepsy had a low mortality rate during first admission, 2.4\% and 0.9\% respectively, the mortality rate raised to $11 \%$ and $16 \%$ after 1-year [21].

In addition to the reported mortality rates, permanent vegetative state or severe disability was an outcome measure in 3 of the 14 studies. For instance, Levy et al. reported a mortality of $61 \%$ of patients, while $12 \%$ of patients remained in permanent vegetative state and $11 \%$ of patients were severely disabled (defined as acceptable cognition but dependent on others for daily support) after 1 year [15]. Hamel et al. reported death in 69\% of patients and severe disability (unable to perform $\geq 4$ activities of daily living) in $20 \%$ of patients after 2 months [19]. Finally, Greer et al. reported 87\% death and 5\% moderate to severe disability as assessed by modified Rankin Scale [14].

Patients with a GCS of 3-5 had a significantly higher probability of death compared to patients with a GCS of 6-8 [12,16]. Forsberg et al. presented similar results. Patients with GCS 3-6 had a significantly higher mortality rate compared to a GCS of 7-10 [21].

\section{Discussion}

We performed a systematic literature review on the etiology and outcome of non-traumatic coma (NTC) over the years 1981-2013. There was only a limited number of publications available on this subject $(n=14)$. The most frequently reported reasons for NTC were stroke, post-anoxic coma, poisoning and metabolic events. Infection appeared to be an important cause of NTC in African countries. Coma etiology and follow-up period influenced the reported NTC mortality rates, which ranged from $25 \%$ to $87 \%$.

\section{Coma etiology}

The most important reasons for NTC appeared to be: stroke, post-anoxic coma, poisoning and metabolic 
Table 1 Characteristics of included prospective observational studies

\begin{tabular}{|c|c|c|c|c|c|c|c|}
\hline Study & $\mathbf{N}$ & Setting & Inclusion & Exclusion & Mortality & $\begin{array}{l}\text { Follow-up } \\
\text { duration }\end{array}$ & Country \\
\hline Esquevin 2013 [6] & 65 & University ED & GCS $\leq 10, \geq 18 \mathrm{yrs}$ & $\begin{array}{l}\text { Trauma, diagnosis such as meningitis, status epilepticus or drug abuse prior to } \\
\text { NCCT and CTA, }>24 \text { hrs between event and NCCT and CTA, contraindication } \\
\text { to iodinated contrast injection, increased or unknown creatinine level }\end{array}$ & $\begin{array}{l}52 \% \text { after } \\
3 \text { months }\end{array}$ & 3 months & France \\
\hline Forsberg 2012 [21]† & 865 & University, non-surgical ED & $\begin{array}{l}\text { GCS } \leq 10 \text { maintained } \\
\text { for } \geq 30 \text { min., } \geq 18 \text { yrs }\end{array}$ & $\begin{array}{l}\text { Coma of unknown cause at discharge or psychogenic, unknown identity of } \\
\text { the patient }\end{array}$ & $27 \%$ & 2 years & Sweden \\
\hline Forsberg $2012[9] \dagger$ & 875 & University, non-surgical ED & $\begin{array}{l}\text { GCS } \leq 10 \text { maintained } \\
\text { for } \geq 30 \text { min., } \geq 18 \text { yrs }\end{array}$ & $\begin{array}{l}\text { Coma of unknown cause at discharge or psychogenic, }>1 \text { plausible coma } \\
\text { etiology }\end{array}$ & $26 \%$ & NS & Sweden \\
\hline Weiss 2012 [18] & 2189 & University ICU & $\begin{array}{l}\text { GCS }<8 \text { in the first } \\
24 \text { hrs of ICU admission }\end{array}$ & & $48 \%$ & $\begin{array}{l}\text { Until } \\
\text { discharge }\end{array}$ & France \\
\hline Forsberg $2009[7] \dagger$ & 938 & University, Non-surgical ED & $\begin{array}{l}\text { GCS } \leq 10 \text { maintained } \\
\text { for } \geq 30 \text { min., } \geq 18 \text { yrs }\end{array}$ & NS & $25 \%$ & $\begin{array}{l}\text { Until } \\
\text { discharge }\end{array}$ & Sweden \\
\hline Greer 2012 [14] & 500 & $\begin{array}{l}\text { University, ED, ICU, } \\
\text { cardiac or neuroscience ICU }\end{array}$ & GCS $<8$ & Coma because of sedating medications or traumatic coma & $\begin{array}{l}87 \% \text { after } \\
6 \text { months }\end{array}$ & 6-months & USA \\
\hline Hamel 1995 [19] & 596 & University hospital or ICU & GCS $\leq 9$ for $\geq 6$ hrs & $\begin{array}{l}\text { Trauma, drug intoxication, hypothermia, operative complication, diabetic } \\
\text { ketotic coma, nonketotic hyperosmolar coma, thyrotoxicosis, myxoedema } \\
\text { coma, hepatic encephalopathy, uraemia, hypo- or hypernatremia, hypo- or } \\
\text { hypercalcaemia. Hospital discharge, death, brain death within } 48 \text { hrs of } \\
\text { study eligibility }\end{array}$ & $\begin{array}{l}69 \% \text { after } \\
2 \text { months }\end{array}$ & 6-months & USA \\
\hline Sacco 1990 [16] & 169 & University ICU & $\mathrm{GCS} \leq 8,>10 \mathrm{yrs}$ & Trauma, acute encephalopathy of unknown cause, coma existing $>72$ hrs & $\begin{array}{l}54 \% \text { after } \\
2 \text { weeks }\end{array}$ & 2-weeks & USA \\
\hline Levy 1981 [15] & 500 & University hospital & $\begin{array}{l}\text { Coma at admission or } \\
\text { during hospitalization, } \\
\geq 12 \text { yrs }\end{array}$ & Trauma, drugs & $\begin{array}{l}64 \% \text { after } \\
1 \text { week }\end{array}$ & 1-year & USA/UK \\
\hline Tokuda 2003 [17] & 115 & Urban teaching hospital ED & $\mathrm{GCS}<8, \geq 15 \mathrm{yrs}$ & Out of hospital cardiac arrest & NS & $\begin{array}{l}\text { Until } \\
\text { discharge }\end{array}$ & Japan \\
\hline Owolabi 2013 [12] & 194 & University, non-surgical ED & $\mathrm{GCS} \leq 8, \geq 18 \mathrm{yrs}$ & Trauma, post anaesthesia coma, coma due to sedative drugs or alcohol & $\begin{array}{l}49 \% \text { after } \\
1 \text { month }\end{array}$ & 1 month & Nigeria \\
\hline Obiako 2011 [10] & 200 & University, ED & $\mathrm{GCS} \leq 8, \geq 16$ yrs & Trauma, inconclusive diagnosis & NS & 28 days & Nigeria \\
\hline Sinclair 1989 [13] & $139 \neq$ & University, ICU & GCS NS, $\geq 18$ yrs & Trauma & NS & $\begin{array}{l}\text { Until } \\
\text { discharge }\end{array}$ & Zambia \\
\hline Matuja 1987 [11] & 150 & University hospital & GCS $\leq 8$ for $\geq 6$ hrs & Transient unresponsiveness, impending death, postictal state, hypoglycaemia & $\begin{array}{l}61 \% \text { after } \\
1 \text { month }\end{array}$ & 1-month & Tanzania \\
\hline
\end{tabular}

$\mathrm{CTA}=$ computed tomographic angiography, ED = emergency department, GCS = Glasgow Coma Scale [7], ICU = intensive care unit, NCCT = noncontrast computed tomography, NS = not specified, POS = prospective observational study, $\mathrm{RS}=$ retrospective study.

† All publications by Forsberg et al. reflect data of the same patient population included between February 2003 and May 2005.

₹ The original publication included 170 patients, however 139 of 153 patients of which GCS was documented were selected for this analysis as only data of GCS $\leq 10$ were included. 
Table 2 Prevalence (in percentages) of non-traumatic coma etiologies

\begin{tabular}{|c|c|c|c|c|c|c|c|c|c|c|c|c|c|}
\hline Study reference & & $\begin{array}{l}\text { Esquevin } \\
{[6]}\end{array}$ & $\begin{array}{l}\text { Forsberg } \\
\text { [9] }\end{array}$ & $\begin{array}{l}\text { Weiss } \\
\text { [18] }\end{array}$ & $\begin{array}{l}\text { Greer } \\
{[14]} \\
\end{array}$ & $\begin{array}{l}\text { Hamel† } \\
\text { [19] }\end{array}$ & $\begin{array}{l}\text { Sacco } \\
{[16]} \\
\end{array}$ & $\begin{array}{l}\text { Levy } \\
{[15]} \\
\end{array}$ & $\begin{array}{l}\text { Tokuda } \\
\text { [17] }\end{array}$ & $\begin{array}{l}\text { Owolabi } \\
\text { [12] }\end{array}$ & $\begin{array}{l}\text { Obiako } \\
{[10]}\end{array}$ & $\begin{array}{l}\text { Sinclair } \\
\text { [13] }\end{array}$ & $\begin{array}{l}\text { Matuja } \\
{[11]} \\
\end{array}$ \\
\hline \multirow[t]{4}{*}{ Structural } & Stroke $^{1}$ & 54 & 24 & 6 & 49 & 51 & $36^{5}$ & 37 & 29 & 24 & 33 & 22 & 13 \\
\hline & CNS infection & 2 & 2 & 3 & - & 6 & - & - & - & 14 & 10 & 19 & 51 \\
\hline & Malignancy & 3 & 2 & - & - & 3 & - & - & $<1$ & 2 & 3 & 1 & - \\
\hline & Other neurological causes & - & - & 1 & - & - & 7 & - & 11 & - & - & 1 & - \\
\hline \multirow{11}{*}{$\begin{array}{l}\text { Metabolic/ } \\
\text { Non-structural }\end{array}$} & Poisoning & - & 39 & 19 & - & $<1$ & - & - & 32 & - & 1 & 15 & 4 \\
\hline & Epilepsy & 5 & 13 & 7 & - & - & - & - & 2 & 4 & - & - & - \\
\hline & Post-anoxic coma & 3 & 7 & 23 & 40 & 31 & 36 & 42 & - & - & 4 & - & - \\
\hline & Respiratory & - & 4 & 8 & - & - & - & - & 5 & - & - & - & - \\
\hline & Infection & - & 4 & - & - & 9 & - & - & 4 & 19 & 11 & - & - \\
\hline & Metabolic ${ }^{2}$ & $31^{4}$ & 4 & 14 & - & 1 & 22 & - & 8 & 21 & 29 & 6 & 5 \\
\hline & Hepatic encephalopathy & - & $<1$ & - & 2 & - & - & 10 & 2 & 8 & 6 & 1 & 20 \\
\hline & Shock & - & - & 21 & - & $<1$ & - & - & - & - & - & - & - \\
\hline & Unclassified $^{3}$ & - & - & $<1$ & - & - & - & - & 2 & 8 & - & 22 & - \\
\hline & Miscellaneous & 3 & - & 1 & 8 & 14 & - & 12 & $<1$ & - & - & - & 8 \\
\hline & Eclampsia & - & - & - & - & - & - & - & - & - & - & 13 & - \\
\hline
\end{tabular}

${ }^{1}$ Stroke includes cerebral infarction, intracerebral hemorrhage and subarachnoid hemorrhage.

${ }^{2}$ The term metabolic includes endocrine, ionic and acid-base disorders and metabolic brain dysfunction (uremic encephalopathy).

${ }^{3}$ Unclassified means that it was not possible to label the event with a diagnosis.

${ }^{4}$ Includes poisoning, metabolic or immune disorders and respiratory failure.

${ }^{5}$ Percentage reflects focal (brain tumour, abscess, infarct, intraparenchymal hemorrhage) and generalized cerebral (meningitis, hydrocephalus, intraventricular hemorrhage, subarachnoid hemorrhage) events.

† More than one coma etiology could be scored in the study, resulting in a total percentage $>100 \%$. 
Table 3 Mortality rates (in percentages) of non-traumatic coma etiologies

\begin{tabular}{|c|c|c|c|c|c|c|c|c|c|}
\hline Study reference & Esquevin [6] & Forsberg [21] & Weiss [18] & Greer [14] & Sacco [16] & Levy [15] & Owolabi [12] & Sinclair [13] & Matuja [11] \\
\hline Stroke & 83 & 60 & 68 & 88 & - & 74 & 69 & 93 & 95 \\
\hline CNS infection & 0 & - & 17 & - & - & - & - & 38 & 39 \\
\hline Poisoning & - & 2 & 7 & - & 0 & - & - & 35 & 67 \\
\hline Epilepsy & 0 & $<1$ & 10 & - & - & - & - & - & - \\
\hline Post-anoxic coma & $50^{2}$ & 72 & 80 & 89 & 54 & 58 & - & - & - \\
\hline Respiratory & - & 61 & 36 & - & - & - & - & - & - \\
\hline Infection & - & 27 & - & - & - & - & - & - & - \\
\hline Metabolic $^{1}$ & 15 & 16 & 20 & - & 48 & - & - & 86 & 43 \\
\hline Hepatic encephalopathy & - & - & - & 80 & - & 49 & - & - & 90 \\
\hline Shock & - & - & 80 & - & - & - & - & - & - \\
\hline Eclampsia & - & - & - & - & - & - & - & 33 & - \\
\hline Unclassified & - & - & - & - & - & - & - & 93 & 100 \\
\hline
\end{tabular}

${ }^{1}$ The term metabolic includes endocrine, ionic and acid-base disorders and metabolic brain dysfunction.

${ }^{2}$ Includes poisoning, metabolic or immune disorders and respiratory failure.

events. However, these categories are rather broad themselves. For example stroke can be divided into ischemic stroke and intracranial hemorrhage. Ischemic stroke has a lower mortality rate than intracerebral hemorrhage. In a large patient cohort $(n=31,629)$ the 30 day mortality was $11 \%$ for ischemic stroke and $37 \%$ for intracerebral hemorrhage [22]. Most included studies in our review lack sufficient detail to allow for a further subdivision of stroke. Nevertheless, it is important to realize that in contrast to hemorrhagic stroke, ischemic stroke only causes coma if the brainstem is involved or if there is a malignant MCA stroke.

Post-anoxic coma was identified as a second important cause of NTC. Generally, post-anoxic coma is the result of an out-of-hospital cardiac arrest. The mortality associated with post-anoxic coma ranged from 54\% to $89 \%$. Some of these differences might be explained by improvements in the care of post-anoxic patients through the years. The introduction of mild therapeutic hypothermia and the improvement of critical care have led to a decline of the hospital mortality of such patients [23]. Again, differences in severity of illness between the cohorts might explain the remainder of the differences in observed mortality.

Poisoning is another major reason for NTC. In the included studies the prevalence of intoxications ranged from $<1 \%$ to $39 \%$. The associated in-hospital mortality was low $(2.4 \%)$ but the one-year mortality was $10.9 \%$. In a recent large observational study of intoxicated patients admitted to the ICU Brandenburg et al. showed similar hospital mortality rates $(2.1 \%)$ but a somewhat lower mortality during follow-up (their 2-year mortality was 9.3\%) [24].

The in-hospital mortality associated with NTC as a result of metabolic derangements ranged from 15 to $86 \%$.
The group of metabolic NTC is a very diverse group but diabetic derangements and hepatic failure are the most prominent causes of metabolic NTC. Clearly, the cause of metabolic NTC is related to outcome. Diabetic ketoacidosis with associated coma is associated with mortality rates $<1 \%$ while hyperglycemic hyperosmolar state is associated with mortality rates of 5-20\% [25]. Hepatic encephalopathy has an even worse prognosis. Fichet et al. included 71 patients with severe hepatic encephalopathy admitted to the intensive care unit (ICU) of which 76\% of patients were admitted with coma (the mean GCS at admission to the ICU was $7.7 \pm 4$ ). During the ICU stay, $35 \%$ of patients died and the 1 year-mortality was $54 \%$ [26].

\section{Limitations}

We tried to include observational cohorts who used similar inclusion criteria for patients with NTC, being a GCS $<10$ and were able to include over 5,000 patients in our systematic review. Of note, Weiss et al. included an important number of patients in their report $(\mathrm{N}=2189)$, which was by far the largest study included in this review [18]. Despite its size, our study has major drawbacks as we found a large variability in the different cohorts and outcomes. This is due to the differences in hospital settings (academic versus urban and the differences in physical setting within the hospital), differences in location (Western world versus Africa) and differences in in- and exclusion criteria for causes of NTC. The latter is illustrated by the exclusion of patients with an intoxication as cause of NTC in some studies, while in other intoxications appeared to be a major contributor to NTC $[6,9,12,14,15,17-19]$. This explains the very low prevalence of drug intoxication and metabolic causes of coma in the SUPPORT cohort of Hamel et al. Even so, within studies including intoxication as cause of 
NTC, there was a large difference in poisoned patients as a cause of NTC. For instance, a prevalence as high as $38 \%$ of patients was reported by Forsberg et al., while $19 \%$ was reported by Weiss et al. This might be due to the difference in coma severity, GCS $\leq 10$ versus GCS < 8 as inclusion criterion in these studies, in addition to the in- and exclusion of specific etiologies in these studies $[7,18]$. Other causes of bias, based on in- and exclusion criteria, are that some studies allowed the inclusion of traumatic causes of coma and some studies also allowed for the coma to arise whilst already hospitalized $[15,17,18]$. Differences in hospital settings are also an important limitation in this analysis. Some hospitals, especially when they are specialized in certain patients' categories, attract more severely ill patients or subgroups of patients. These differences will undoubtedly be reflected in the composition of the study population as well as their outcomes. In addition, it is important to identify the difference in organization structure and length of stay on the emergency department before the patient is admitted to the ICU. If patients only stayed a few hours in the emergency department and are subsequently transferred to the ICU, the outcome of the emergency department will be different from another emergency department that treats such patients for several days on the ED. Such organizational differences are very important to consider but very few studies provide these details. The relationship between NTC etiology and outcome might be further obscured if studies allow hospitalized patients to be admitted to the ICU or the ED. Again, such details are often lacking. We have included all patients with NTC who were admitted to the ED and/or ICU irrespective of the time spent on the ED.

Another major limitation is that some studies were over 25 years old. These results may no longer reflect current outcome as the care of critically ill patients has improved significantly over the last decades.

Finally, some publications unfortunately appeared to have studied the same population. For example, Forsberg et al. had three publications based on largely the same patient dataset. These three studies contained different etiological and prognostic data and were all included in our review $[7,9,21]$.

\section{Conclusions}

We have shown that the currently studied cohorts hamper thorough conclusion making on the NTC etiology and mortality as the patient cohorts were too heterogeneous. Despite these limitations, we advise to focus the diagnostic work-up in patients with NTC on: (1) stroke, (2) postanoxic coma, (3) poisoning and (4) metabolic events, because these were the most important causes of NTC.

Clearly, a swift and adequate work-up in the diagnosis of NTC on the emergency department and ICU might improve outcome of such patients. Ideally, the diagnostic work-up aims to first identify those causes of NTC, where time is of essence and patients have the highest chances of clinical improvement if the cause of NTC is identified quickly. We therefore advocate that more standardized patient cohort studies are necessary to be able to confirm which etiologies are the most prominent in NTC and using solid endpoints to register morbidity and mortality in a standardized manner. These studies should include all patients presenting with NTC at the hospital, irrespective of the cause of NTC, and fixed outcome end-points should be used. Only so, will future opportunities for the improvement of patient outcome be identified in patients with NTC.

\section{Additional file}

Additional file 1: Database search entries in Pubmed, Embase and Cochrane search engines.

\section{Abbreviations}

CNS: Central nervous system; CTA: Computed tomographic angiography; ED: Emergency department; GCS: Glasgow Coma Scale; HIV: Human immunodeficiency virus; ICU: Intensive care unit; NCCT: Noncontrast computed tomography; NS: not specified; NTC: non-traumatic coma; POS: prospective observational study; RS: retrospective study; MESH: Medial Subject Headings; UK: United Kingdom; USA: United States of America.

\section{Competing interests}

The authors declare that they have no competing interests.

\section{Authors' contributions}

$\mathrm{MH}$ performed the systematic literature search and drafted the manuscript, MF performed the design of data collection, the systematic literature search and drafted the manuscript, JM revised the content of the manuscript, WK revised the content of the manuscript, DL contributed to the design of data collection, helped draft the manuscript and revised the content of the manuscript. All authors read and approved the final manuscript.

\section{Author details}

${ }^{1}$ Division of Anaesthesiology, Intensive Care and Emergency Medicine, University Medical Centre Utrecht, mailstop Q04.2.313, PO Box 85500, 3508 GA Utrecht, Netherlands. ${ }^{2}$ Department of Intensive Care Medicine and National Poison Information Center, University Medical Center Utrecht, Heidelberglaan 100, 3584 CX, Utrecht, Netherlands.

Received: 13 November 2014 Accepted: 20 April 2015

Published online: 29 April 2015

\section{References}

1. Stevens RD, Bhardwaj A. Approach to the comatose patient. Crit Care Med. 2006;34(1):31-41

2. Kanich W, Brady WJ, Huff JS, Perron AD, Holstege C, Lindbeck G, et al. Altered mental status: evaluation and etiology in the ED. Am J Emerg Med. 2002;20(7):613-7.

3. Teasdale $G$, Jennett B. Assessment of coma and impaired consciousness. A practical scale. Lancet. 1974;2((7872):81-4.

4. Edlow JA, Rabinstein A, Traub SJ, Wijdicks EF. Diagnosis of reversible causes of coma. Lancet. 2014;384(9959):2064-76.

5. Wijdicks EF. The bare essentials: coma. Neurol Pract. 2010;10(1):51-60.

6. Esquevin A, Raoult H, Ferre JC, Ronziere T, Stamm A, Perennes M, et al. Systematic combined noncontrast CT-CT angiography in the management of unexplained nontraumatic coma. Am J Emerg Med. 2013;31(3):494-8. 
7. Forsberg S, Hojer J, Enander C, Ludwigs U. Coma and impaired consciousness in the emergency room: Characteristics of poisoning versus other causes. Emerg Med J. 2009;26(2):100-2.

8. Forsberg $\mathrm{S}$, Hojer J, Ludwigs U. Hospital mortality among poisoned patients presenting unconscious. Clin Toxicol (Phila). 2012;50(4):254-7.

9. Forsberg S, Hojer J, Ludwigs U, Nystrom H. Metabolic vs structural coma in the ED - An observational study. Am J Emerg Med. 2012;30(9):1986-90.

10. Obiako OR, Oparah S, Ogunniyi A. Causes of medical coma in adult patients at the University College Hospital. Ibadan Nigeria Niger Postgrad Med J. 2011;18(1):1-7.

11. Matuja WB, Matekere NJ. Causes and early prognosis of non-traumatic coma in Tanzania. Muhimbili Medical Centre experience. Trop Geogr Med. 1987;39(4):330-5.

12. Owolabi LF, Mohammed AD, Dalhat MM, Ibrahim A, Aliyu S, Owolabi DS. Factors associated with death and predictors of 1-month mortality in nontraumatic coma in a tertiary hospital in Northwestern Nigeria. Indian J Crit Care Med. 2013;17(4):219-23.

13. Sinclair JR, Watters DA, Bagshaw A. Non-traumatic coma in Zambia. Trop Doct. 1989;19(1):6-10.

14. Greer DM, Yang J, Scripko PD, Sims JR, Cash S, Kilbride R, et al. Clinical examination for outcome prediction in nontraumatic coma. Crit Care Med. 2012;40(4):1150-6.

15. Levy DE, Bates D, Caronna JJ, Cartlidge NE, Knill-Jones RP, Lapinski RH, et al. Prognosis in nontraumatic coma. Ann Intern Med. 1981;94(3):293-301.

16. Sacco RL, VanGool R, Mohr JP, Hauser WA. Nontraumatic coma. Glasgow coma score and coma etiology as predictors of 2-week outcome. Arch Neurol. 1990;47(11):1181-4.

17. Tokuda Y, Nakazato N, Stein GH. Pupillary evaluation for differential diagnosis of coma. Postgrad Med J. 2003;79(927):49-51.

18. Weiss N, Regard L, Vidal C, Luque Y, Taldir G, Vallet H, et al. Causes of coma and their evolution in the medical intensive care unit. J Neurol. 2012;259(7):1474-7.

19. Hamel MB, Goldman L, Teno J, Lynn J, Davis RB, Jr. Harrell FE, et al. Identification of comatose patients at high risk for death or severe disability. SUPPORT Investigators. Understand Prognoses and Preferences for Outcomes and Risks of Treatments. JAMA. 1995;273(23):1842-8.

20. Jennett $B$, Bond M. Assessment of outcome after severe brain damage. Lancet. 1975;1(7905):480-4.

21. Forsberg S, Hojer J, Ludwigs U. Prognosis in patients presenting with nontraumatic coma. J Emerg Med. 2012;42(3):249-53.

22. Xian Y, Holloway RG, Pan W, Peterson ED. Challenges in assessing hospitallevel stroke mortality as a quality measure: comparison of ischemic, intracerebral hemorrhage, and total stroke mortality rates. Stroke. 2012;43(6):1687-90.

23. Nielsen N, Wetterslev J, Cronberg T, Erlinge D, Gasche Y, Hassager C, et al. Targeted temperature management at 33 degrees $C$ versus 36 degrees $C$ after cardiac arrest. N Engl J Med. 2013;369(23):2197-206.

24. Brandenburg R, Brinkman S, de Keizer NF, Meulenbelt J, de Lange DW. In-Hospital Mortality and Long-Term Survival of Patients with Acute Intoxication Admitted to the ICU. Crit Care Med. 2014;6:1471-9.

25. Nyenwe EA, Kitabchi AE. Evidence-based management of hyperglycemic emergencies in diabetes mellitus. Diabetes Res Clin Pract. 2011;94(3):340-51.

26. Fichet J, Mercier E, Genee O, Garot D, Legras A, Dequin PF, et al. Prognosis and 1-year mortality of intensive care unit patients with severe hepatic encephalopathy. J Crit Care. 2009;24(3):364-70.

\section{Submit your next manuscript to BioMed Central and take full advantage of:}

- Convenient online submission

- Thorough peer review

- No space constraints or color figure charges

- Immediate publication on acceptance

- Inclusion in PubMed, CAS, Scopus and Google Scholar

- Research which is freely available for redistribution 